\title{
Introduction to the Special Issue: Urban Mobility and Crime Patterns
}

\author{
Andrew Newton ${ }^{1}$ (D) $\cdot$ Marcus Felson $^{2} \cdot$ Jon Bannister ${ }^{3}$
}

Accepted: 5 November 2021 / Published online: 16 November 2021

(c) The Author(s), under exclusive licence to Springer Nature B.V. 2021

\begin{abstract}
This Special Issue is a collection of seven papers that seek to better our understanding of how urban mobility relates to crime patterns, and how day to day movement of people in urban spaces (urban mobility) is related to spatio-temporal patterns of crime. It focusses on urban mobility, or the dynamic movement of people in relation to crime risk. Moreover, it questions how to best measure this risk using an appropriate crime denominator. Building on the work of Sarah Boggs, this special issue contends that we need more than an appropriate denominator related to the type of crime we are measuring, for example violence based on the number of potential victims present (the exposed or ambient population), or the number of burglaries per households in an area, or the number of shoplifting offences per number of shops present. It argues that this denominator needs to be both 'crime type' appropriate, and to be spatially and temporally appropriate. When considering urban mobility as flows of people, the challenge is that the denominator can not be considered as a fixed or static concept, and that we need to consider the 'dynamic denominator' challenge. Indeed, crime hot spots which do not account for dynamic denominators may be misleading for resource prioritisation. This special issue explores a range of potential solutions to this including mobile/cell phone data, transportation data, land use data, and other possible measures to address this.
\end{abstract}

Keywords Crime $\cdot$ Hot spots $\cdot$ Spatio-temporal crime hot spots $\cdot$ Urban mobility $\cdot$ Crime denominators $\cdot$ Exposed population $\cdot$ Ambient population

Andrew Newton

andy.newton@ntu.ac.uk

1 Department of Criminology and Criminal Justice (CCJ), School of Social Sciences, Nottingham

Trent University, Room 3011, Chaucer Building, 50 Shakespeare Street, Nottingham NG1 4FQ, UK

2 Texas State University, San Marcos, TX, USA

3 Manchester Metropolitan University, Manchester, UK 


\section{Introduction to the Special Issue}

The purpose of this special issue is to better understand the spatial and temporal concentrations of crime (hot spots) and urban mobility, in other words the relationship between crime patterns and how people move about urban places. A previous Special Issue (Newton \& Felson, 2015) sought to better understand the spatiotemporal patterns in crime, and this Special Issue develops this further by exploring to what extent spatiotemporal crime patterns are driven by underlying changes in urban mobility. The contention is that to better assess crime risk, we should go further than understanding the dynamic spatiotemporal patterns of crime. We need to consider this alongside the dynamic nature of denominators of crime, in other words the changing patterns of populations and potential targets/victims of crime and offenders.

This Special Issue was conceived before the outset of COVID-19, and the data analysed in the papers are generally pre-COVID-19. Several recent publications have demonstrated how during the pandemic, routine activities, and lifestyles have been disrupted due to COVID-19 and the implementation of a range of differing lockdown policies. Globally, these have varied both in the timing of the measures, and the types of restrictions introduced. When examining outdoor crime, the general pattern has been of reduced levels of crime during periods of lockdown, although this has varied by location and crime type (Nivette, et al, 2021). However, papers exploring changing crime patterns due to COVID19 have rarely had access to data to associate change between micro-level crime patterns and changes in urban mobility at a similar scale. Most studies have explored crime frequencies and compared this to periods of lockdown. Efforts have been afforded to consider population denominators (Halford et al., 2020; Langton et al., 2021) drawing on google mobility data and ambient population data. These are approximated for denominators locally, and thus questions remain as to whether these measures represent appropriate temporal and spatial scales for understanding micro-level changes in urban mobility. Therefore, this Special Issue is pertinent as it explores in more detail how to better measure and understand dynamic patterns of urban mobility and its relationship with spatiotemporal crime patterns-what can be termed the 'dynamic denominator challenge'.

Within criminology research, much attention has been focussed on the limitations of crime counts (raw frequencies), and there is a paucity of studies that explicitly addressed the limitations of the denominators used to calculate crime rates (Telep \& Hibdon, 2017). Most studies that use crime rates use the residential census population (offences per 10,000 persons) or number of houses (burglary per 1000 dwellings), yet residential census counts are clearly not representative of persons present and those at risk of a crime at different times of the day. Crime is traditionally measured in one of three ways:

- Crime frequencies (the count of the number of offences in a particular area over defined time period)

- Crime rates (the count of the number of offences divided by a population denominator-usually household population or residential population based on census data. Again, this is for particular location and over a defined time period, e.g. burglaries per thousand households, or violence per 10,000 persons)

- Crime prevalence-percentage of all crime, e.g. burglary as proportion of all crimes

When considering crime rates, how does this risk vary during the day, when people are out for leisure activities, at work or school, or when tourists are present. Indeed, 
crime counts, and the crime hot spots generated from these frequencies, neglect to consider the actual population a risk of crime, those people who are present at that time and at that location. For example, whilst Oxford Street in London may experience over 1000 shoplifting offences per month, this needs to be put into context that it experiences approximately half a million visitors per day. The London Underground experiences nearly 5000 theft offences per year, yet this is a rate of 4 thefts per million passenger journeys (Newton et al., 2014). Moreover, as crime is known to concentrate not only spatially but temporally, what is required is a better understanding of the daily and weekly fluctuations of crime and populations. For example, how does the number of shoplifting offences on Saturday $3.00 \mathrm{pm}$ to $4.00 \mathrm{pm}$, versus midnight to 6.00am, relate to changes in population. How does pickpocketing at $4.00 \mathrm{pm}$ on a Friday compare to midnight on a Sunday (Newton \& Felson, 2015). This Special Issue attempts to better examine how urban mobility influences crime rates and the population at risk in urban centres.

A range of theoretical approaches may help to unravel some of the complexities of urban mobility and crime. These include lifestyle theory, routine activities (discretionary and obligatory), crime pattern theory and rational choice, and collective efficacy and social cohesion (Andresen, 2011; Boggs, 1965; Cohen \& Felson, 1979; Sherman et al., 1989). However, the dynamic nature of urban landscapes and the growth of more nuanced data allows more refined analysis and empirical testing of some of these theoretical approaches. What appears at the outset to be a 'simple' place can be highly dynamic. To demonstrate this, consider the changing usage of a bus stop by time of day using a UK example. From $7.00 \mathrm{am}$ to $9.00 \mathrm{am}$, typical users are commuters and school children. From 9.30am to $3.00 \mathrm{pm}$ in the UK, users include those who are retired and entitled to free travel and a mix of other users. From $3.00 \mathrm{pm}$ to $5.00 \mathrm{pm}$, school children travelling home dominate public transport, and this shifts to commuters travelling home from $5.00 \mathrm{pm}$ to $7.00 \mathrm{pm}$. After $7.00 \mathrm{pm}$, public transport is predominantly used by those at the start of the night-time economy, those working in the NTE, and consumers of it. This poses several questions for crime such as what population is at risk of crime; how crime risk varies temporally, by hour of the day and day of week or by the 168-h crime week (Newton, 2015); and how much does the underlying population at risk differ from standard residential populations traditionally used to measure crime. This Special Issue contains seven papers that explore this topic.

Three of the papers in this Special Issue explore daily rhythms and population flows and their relationship to crime. Lee et al. (2020) explore 'the influence of intra-daily activities and settings upon weekday violent crime in public spaces in Manchester, UK'. They use negative binomial regression models controlling for spatial lag effects to explore associations between leisure activities, leisure settings, and spatiotemporal patterns of violence crime in public space (outdoor). Haleem et al. (2020) move beyond these activity settings to examine 'the exposed population, violent crime in public space and the night-time economy in Manchester, UK'. In this paper, they attempt to capture and delineate a violencespecific population denominator. They compare this exposed population between Wednesday (midweek) and Saturday to explore how the 'at-risk' population shifts. A third paper explicitly addressing these population flows is a paper by Gerell (2021): 'Does the Association Between Flows of People and Crime Differ Across Crime Types in Sweden?'. This paper seeks to understand how flows of people in Malmo, Sweden, relate to travel patterns across six different crime types: robbery, assault, bike theft, theft from car, vandalism, and arson. All three of these papers identify associations between daily population flows (i.e. urban mobility) and crime. 
Three of the papers in the Special Issue make use of 'big data' by utilising mobile phone day to analyse urban mobility patterns. Johnson et al. (2020) examine 'Cell towers and the ambient population: a spatial analysis of disaggregated property crime' to explore differences between the ambient and residential population for five types of property crime. They suggest that prevention measures that identify population at risk of burglary using residential population data are misleading and may have no impact on or even may increase burglary. Haleem et al. (2020) and Lee et al. (2020) use a mobile phone origin destination (MPOD) dataset to quantify transient population flows by creating synthesised daily trip chaining data. These are integrated with land use data to develop activity settings and a measure of the at risk or 'exposed population' for violence. Interestingly, the terms ambient population and exposed population are used by the authors to express 'at-risk' populations, and it would be useful in future work to consider how we can develop consistent terminology when discussing the impact of 'dynamic' population denominators.

Three of the papers make use of public transport data. Gerell (2021) uses bus stop patronage to consider population flows and its relationship with crime although this is used for more general crime outside of the transport network. Ceccato and Moreira (2020) examine 'the dynamics of thefts and robberies in São Paulo's Metro, Brazil'. They examine the nature of spatiotemporal theft and robbery at transport nodes in Brazil and identify how transport nodes positionality on the network-again related to daily population flow and urban mobility impacts on the levels of these two crimes. They also examine crime at these transport nodes and near to the nodes, which ties in with Bowers (2014) concept of crime radiators and absorbers. Indeed, transport nodes may act as a radiator for crime, strongly influences by the flows and troughs of passengers arriving and leaving transport nodes. Herrmann et al (2021) also explore the transport network with their paper 'subway station closures and robbery hot spots in New York cityunderstanding mobility factors and crime reduction' examining robberies in and around subway stations in New York. This paper explores the impact of temporary closures of these stations as a direct influence on local mobility patterns and therefore the 'at-risk' population. They identify substantial reductions in robbery during temporary closures, and that these are more pronounced closer to subway stations.

A final paper by Vaughan et al. (2020) makes use of an alternative measures of crime, and rather than examining police recorded crime or calls for service, this paper considers victimisation surveys as an alternative measure. They examine 'the promise and challenge of activity-based crime rates: a comparison of the USA, Canada, and Australia'. This approach highlights the types of activities carried out that puts users at most risk, and rates can be calculated based on the number of hours spend during these activities. Indeed, they identify that the duration people spend on leisure, travel, and other activities outside the home can have a marked impact on victimisation. Moving forwards, the findings of this paper, combined with the Haleem et al. (2020) and Lee et al. (2020) studies - that identified activity settings by combining travel data with land use-suggest the length of time people spend at certain settings and the number of people at these 'at-risk' settings are fundamental for understanding spatial and temporal patterns of crime. Moreover, as highlighted by Boggs over fifty years ago and demonstrated by all papers in this Special Issue, these 'at-risk' populations will vary by crime type. The challenge moving forwards is how to develop appropriate crime-specific and dynamic population denominators that are appropriate in scale both geographically and temporally. 


\section{Declarations}

Conflict of Interest The authors declare no competing interests.

\section{References}

Andresen, M. (2011). The ambient population and crime analysis. The Professional Geographer, 63, $193-212$.

Boggs, S. L. (1965). Urban crime patterns. American Sociological Review, 30, 899-908.

Bowers, K. (2014). Risky facilities: Crime radiators or crime absorbers? A comparison of internal and external levels of theft. Journal of Quantitative Criminology., 30, 389-414.

Cohen, L. E., \& Felson, M. (1979). Social change and crime rate trends: A routine activity approach. American Sociological Review, 44(4), 588-608.

Halford, E., Dixon, A., Farrell, G., et al. (2020). Crime and coronavirus: Social distancing, lockdown, and the mobility elasticity of crime. Crime Science, 9, 11.

Langton, S., Dixon, A., \& Farrell, G. (2021). Six months in: Pandemic crime trends in England and Wales. Crime Science, 10, 6.

Newton, A., \& Felson, M. (2015). Editorial: Crime patterns in time and space: the dynamics of crime opportunities in urban areas. Crime Science, $4,11$.

Newton, A., Partridge, H., \& Gill, A. (2014). In and around: Identifying predictors of theft within and near to major mass underground transit systems. Security Journal, 27(2), 132-146.

Newton, A. (2015). Crime and the NTE: Multi-classification crime (MCC) hot spots in time and space. Crime Science, 4, 30.

Nivette, A. E., Zahnow, R., Aguilar, R., et al. (2021). A global analysis of the impact of COVID-19 stay-athome restrictions on crime. Nature Human Behaviour, 5, 868-877.

Sherman, L. W., Gartin, P. R., \& Buerger, M. E. (1989). Hot spots of predatory crime: Routine activities and the criminology of place. Criminology, 27, 27.

Telep, C. W., \& Hibdon, J. (2017). Identifying and responding to hot spots: Are crime counts enough? Criminology \& Public Policy, 16, 661-671.

\section{Papers in this Special Issue}

Ceccato, V., Moreira, G. (2020) the dynamics of thefts and robberies in São Paulo's Metro, Brazil. European Journal on Criminal Policy and Research https://doi.org/10.1007/s10610-020-09462-3

Gerell, M. (2021). Does the association between flows of people and crime differ across crime types in Sweden? European Journal on Criminal Policy and Research. https://doi.org/10.1007/s10610-021-09478-3

Haleem, M.S., Do Lee, W., Ellison, M. et al. (2020) The 'exposed' population, violent crime in public space and the night-time economy in Manchester, UK. European Journal on Criminal Policy and Research. https://doi.org/10.1007/s10610-020-09452-5

Herrmann, C. R., Maroko, A. R., \& Taniguchi, T. A. (2021). Subway station closures and robbery hot spots in New York City-Understanding mobility factors and crime reduction. European Journal on Criminal Policy and Research. https://doi.org/10.1007/s10610-020-09476-X

Johnson, P., Andresen, M. A., \& Malleson, N. (2020). Cell towers and the ambient population: A spatial analysis of disaggregated property crime. European Journal on Criminal Policy and Research. https:// doi.org/10.1007/s10610-020-09446-3

Lee, W., Haleem, M.S., Ellison, M. et al. (2020) The influence of intra-daily activities and settings upon weekday violent crime in public spaces in Manchester, UK. European Journal on Criminal Policy and Research https://doi.org/10.1007/s10610-020-09456-1

Vaughan, A. D., Hart, T. C., Hewitt, A. N., et al. (2020). The promise and challenge of activity-based crime rates: A comparison of the USA, Canada, and Australia. European Journal on Criminal Policy and Research. https://doi.org/10.1007/s10610-020-09461-4

Publisher's Note Springer Nature remains neutral with regard to jurisdictional claims in published maps and institutional affiliations. 